\title{
Acid regulates inflammatory response in a rat model of induction of gastric ulcer recurrence by interleukin $1 \beta$
}

\author{
T Watanabe, K Higuchi, K Tominaga, Y Fujiwara, T Arakawa
}

\begin{abstract}
Background-In a previous study we showed that interleukin $1 \beta$ (IL-1ß) caused recurrence of gastric ulcers in rats, and that adhesion molecules (intercellular adhesion molecule 1 and leucocytic $\beta 2$ integrins) play a role in this recurrence. Although gastric acid plays an important role in many types of gastric injuries, including peptic ulcer recurrence, the mechanism(s) remains unclear.

Aims-To examine the involvement of gastric acid in induction of ulcer recurrence by IL-1 $\beta$, and to investigate the role of gastric acid in inflammatory responses during ulcer recurrence.

Methods-Rats with healed ulcers were used. Rats were given $1 \mu \mathrm{g} / \mathrm{kg}$ IL-1 $\beta$ intraperitoneally. Another group of rats was given $20 \mathrm{mg} / \mathrm{kg}$ omeprazole for three days to inhibit acid secretion, and received IL-1及 20 hours after the first administration of omeprazole. They were then given $0.15 \mathrm{~N} \mathrm{HCl}$ or vehicle at $0,12,24$, and 36 hours after IL-1 $\beta$ treatment. Some rats were given acid alone at the same time points. Expression of adhesion molecules was examined immunohistochemically and concentrations of IL-1 $\beta$ and tumour necrosis factor $\alpha$ (TNF- $\alpha)$ were measured by ELISA in scar tissue 24 hours after IL-1 $\beta$ treatment.
\end{abstract}

Results-IL-1 $\beta$ increased expression of adhesion molecules and concentrations of IL-1 $\beta$ and TNF- $\alpha$ in scar tissue by 24 hours after IL-1 $\beta$ treatment, and nine of 11 healed ulcers had recurred by 48 hours. Omeprazole inhibited the effects of IL-1ß. $\mathrm{HCl}$ acid abolished the inhibitory effects of omeprazole. Acid alone affected neither expression of adhesion molecules nor cytokine concentrations, and did not cause recurrence.

Conclusions-Gastric acid is required for recurrence of gastric ulcers caused by IL-1 $\beta$, and gastric acid stimulates the inflammatory process in scarred mucosa during ulcer recurrence. (Gut 2001;48:774-781)

Keywords: ulcer recurrence; gastric acid; inflammatory cytokines; adhesion molecules; inflammation

The mechanism(s) by which peptic ulcers recur is still unclear. Maintenance treatment with histamine $\mathrm{H}_{2}$ receptor antagonists or proton pump inhibitors (PPIs) reduced the rate of peptic ulcer recurrence in humans. ${ }^{12}$ As these drugs alone cannot eradicate Helicobacter pylori, a major cause of ulcer recurrence, these clinical findings indicate that gastric acid plays a crucial role in peptic ulcer recurrence. However, the mechanism by which gastric acid induces gastric damage and ulcer recurrence is not known.

We recently developed a rat model of induction of gastric ulcer recurrence by interleukin $1 \beta$ (IL-1 $\beta$ ). ${ }^{3}$ This model of ulcer recurrence is useful for investigating the pathogenesis of peptic ulcer recurrence as approximately $80-100 \%$ of healed ulcers recur at sites of scarred mucosa within 48 hours after injection of IL-1 $\beta$. This process is neutrophil dependent, and specific monoclonal antibodies against intercellular adhesion molecule 1 (ICAM-1) and leucocytic $\beta 2$ integrins, lymphocyte function associated antigen 1 (LFA-1, CD11a/ CD18) or Mac-1 (CD11b/CD18), reduced both neutrophil infiltration into scarred mucosa and induction of ulcer recurrence by IL- $1 \beta .^{3}$ These adhesion molecules, which are present on both endothelial cells and leucocytes, thus play a role in IL-1 $\beta$ induced ulcer recurrence. However, it is not known if gastric acid plays a role in ulcer recurrence and stimulation of mucosal inflammation induced by IL-1 $\beta$.

Cytokines such as IL- $1 \beta$ and tumour necrosis factor $\alpha(\mathrm{TNF}-\alpha)$ are key cytokines in many inflammatory processes, ${ }^{4-6}$ and can upregulate adhesion molecules. ${ }^{7}$ As leucocytes, especially neutrophils, infiltrate the superficial portion of scarred mucosa prior to induction of ulcer recurrence by IL-1 $\beta,{ }^{3}$ we hypothesised that overexpression of both adhesion molecules and cytokines occurs in the superficial portion of scarred mucosa during development of ulcer recurrence.

In the present study, to confirm the involvement of gastric acid in ulcer recurrence, and to evaluate the mechanism of acid induced gastric mucosal injury, we investigated the effect of omeprazole, a PPI which strongly inhibits gastric acid secretion, on gastric ulcer recurrence induced by IL- $1 \beta$ in rats. We also evaluated expression of adhesion molecules (ICAM-1, LFA-1, and Mac-1) and cytokines (IL-1 $\beta$ and TNF- $\alpha$ immunohistochemically, and measured concentrations of cytokines in scarred mucosa after treatment with IL-1 $\beta$.

Abbreviations used in this paper: IL, interleukin; TNF, tumour necrosis factor; ICAM-1, intercellular adhesion molecule 1; LFA-1, lymphocyte function associated antigen 1; PPI, proton pump inhibitor. 


\section{Materials and methods}

ANIMALS AND ULCER INDUCTION

Specific pathogen free male Wistar rats weighing about $200 \mathrm{~g}$ were obtained from Japan SLC, Inc. (Hamamatsu, Japan). Chronic gastric ulcers were induced by the method of Takagi and colleagues. ${ }^{8}$ Under ether anaesthesia, the abdomen was incised and the stomach exposed. Then $0.02 \mathrm{ml}$ of $20 \%$ acetic acid was injected into the submucosal layer of the antral oxyntic border of the anterior wall and the abdomen was closed. All experimental procedures were approved by the Animal Care Committee of Osaka City University Medical School.

EXPERIMENTAL GROUPS

Endoscopy was performed by the method of Fukawa and colleagues ${ }^{9}$ on day 90 after induction of ulcers. Animals were deprived of food but not water for 18-22 hours before endoscopy. A needle type endoscope (SES-1717S, Olympus Optical Co., Ltd, Tokyo, Japan) was inserted into the stomach from the mouth, and the inside of the stomach was observed. Ulcers without a white coat were considered healed while ulcers with a white coat after treatment were considered recurrent ulcers.

Rats with healed ulcers were subjected to experiments on induction of ulcer recurrence. Twelve animals with healed ulcers were killed without treatment with IL-1 $\beta$ (control) and underwent immunohistochemical study $(n=6)$ and measurement of cytokine concentrations $(n=6)$. The remaining animals were randomly divided into four groups $(n=18-23)$. For positive control rats (group 1), $1 \mu \mathrm{g} / \mathrm{kg}$ recombinant human IL-1 $\beta$ (Genzyme, Boston, Massachusetts, USA) diluted to $1 \mathrm{ml}$ with isotonic phosphate buffered saline was injected intraperitoneally. Rats in groups 2 and 3 were given $20 \mathrm{mg} / \mathrm{kg}$ omeprazole, a gift from Astra Japan (Osaka, Japan), by gavage for three days to sufficiently inhibit gastric acid secretion, ${ }^{10}$ and received an intraperitoneal injection of $\mathrm{IL}-1 \beta$ 20 hours after the first administration of omeprazole. They were then given distilled water $(0.5 \mathrm{ml} / 100 \mathrm{~g}$, group 2) or the same volume of $0.15 \mathrm{~N} \mathrm{HCl}$ (group 3) by gavage at 0 , 12,24 , and 36 hours after IL-1 $\beta$ treatment (group 2). In group 4, rats were given $0.15 \mathrm{~N}$ $\mathrm{HCl}(0.5 \mathrm{ml} / 100 \mathrm{~g})$ at $0,12,24$, and 36 hours after intraperitoneal injection of vehicle alone. Twelve animals in each group were killed 24 hours after intraperitoneal injection of IL- $1 \beta$ or vehicle, and underwent immunohistochemical study $(n=6)$ and measurement of cytokine concentrations $(n=6)$. The remaining rats were killed 48 hours later. Some rats in group 4 were killed 60 hours $(n=5)$ and 84 hours $(n=6)$ after administration of vehicle. We also examined the effect of concurrent administration of exogenous acid with IL- $1 \beta$ on ulcer recurrence. Six rats were given $0.15 \mathrm{~N} \mathrm{HCl}(0.5 \mathrm{ml} / 100 \mathrm{~g})$ by gavage at $0,12,24$, and 36 hours after intraperitoneal injection of IL-1 $\beta$ (group 5) and were killed 48 hours later after injection of IL- $1 \beta$.

In our previous study, surface epithelium was disrupted at sites of neutrophil accumulation by 24 hours after IL- $1 \beta$ treatment. ${ }^{3}$ This finding suggests that ulcer recurrence or mucosal injury starts by 24 hours after IL- $1 \beta$ treatment. As leucocytes, including neutrophils, express both LFA-1 and Mac-1, we examined the effect of in vivo blocking of ICAM-1 on infiltration of leucocytes which express LFA-1 or Mac-1 into scarred mucosa after injection of IL-1 $\beta$. Antibody against ICAM-1 (1A29) ${ }^{11}$ was purchased from Seikagakukogyo Co. (Tokyo, Japan). The antibody against ICAM-1 was used as the $\mathrm{F}\left(\mathrm{ab}^{\prime}\right)_{2}$ fragments of $\operatorname{IgG}_{1}$. Rats were given $75 \mathrm{mg}$ of $\mathrm{F}(\mathrm{ab})_{2}$ of the antibody intravenously at 0 and 12 hours after IL-1 $\beta$ treatment and were killed 24 hours later $(n=6)$.

ANALYSIS OF GASTRIC ACID SECRETION

Gastric acid secretion was measured in rats given IL- $1 \beta$ and rats given both IL- $1 \beta$ and omeprazole. Omeprazole was administered at a dose of $20 \mathrm{mg} / \mathrm{kg}$ by gavage 20 hours before and four hours after intraperitoneal injection of $1 \mu \mathrm{g} / \mathrm{kg}$ IL- $1 \beta$ or vehicle. The pylorus was ligated 0 or 20 hours after treatment with IL-1 $\beta$ or vehicle, and rats were killed four hours after ligation $(n=6)$. The volume was measured and concentration of acid was determined by titration with $0.01 \mathrm{~N} \mathrm{NaOH}$ with an automatic titration system (AUT-301L, TOA Electronics, Ltd, Tokyo, Japan).

IL-1 $\beta$ AND TNF- $\alpha$ ASSAYS

Rats in groups 1-4 were killed 24 hours after injection of IL-1 $\beta$ or vehicle, and scar tissue and normal gastric tissue distant from scarred mucosa were removed separately $(n=6)$. Concentrations of both IL- $1 \beta$ and TNF- $\alpha$ in homogenate supernatants were determined by solid phase sandwich enzyme linked immunosorbent assay (both from Cosmo Bio Co., Ltd, Tokyo, Japan) according to the manufacturer's instructions. Minimum detectable levels of IL- $1 \beta$ and TNF- $\alpha$ were $<3 \mathrm{pg} / \mathrm{ml}$ and $<0.7$ $\mathrm{pg} / \mathrm{ml}$, respectively. Interassay variabilities for both assays were less than $7 \%$. The assays have no cross reactivity with other rat cytokines or cytokines of other species, including human IL-1 $\beta$. In addition, we confirmed in a preliminary study that human recombinant IL-1 $\beta$, which was administered to rats in this study, did not interfere with the assays. Proteins were measured using a modified bicinchoninic acid method $^{12}$ with a BCA protein assay reagent kit (Pierce, Rockford, Illinois, USA). Concentrations of IL- $1 \beta$ and TNF- $\alpha$ in scar tissue are expressed as $\mathrm{ng} / \mathrm{mg}$ protein.

IMMUNOHISTOCHEMICAL STUDY

Cryostat sections cut serially ( $6 \mu \mathrm{m}$ thick) were mounted on silanised slides (Dako Japan Co., Ltd, Kyoto, Japan). Mouse monoclonal antibodies against rat LFA-1 $\alpha$ chain (CD11a), WT.1 (Seikagakukogyo Co.), Mac-1 $\alpha$ chain (CD11b, ED8; Serotec, Oxford, UK), and ICAM-1 (CD54, 1A29; Seikagakukogyo Co.) were used for detection of adhesion molecules. Mouse monoclonal antirat IL-1 $\beta$ antibody (Serotec) and rabbit polyclonal antimouse TNF- $\alpha$ (Genzyme) were used for identification of cells which produced these cytokines. 
Table 1 Ulcer recurrence rate at 48 hours after administration of interleukin $1 \beta$ (IL-1 $\beta)$ treatment

\begin{tabular}{lll}
\hline Group & Treatment & No recurred/treated (\%) \\
\hline 1 & IL-1 $\beta$ (positive control) & $9 / 11(82)$ \\
2 & IL-1 $\beta+\mathrm{OPZ}$ & $0 / 9(0)^{\star}$ \\
3 & IL-1 $\beta+\mathrm{OPZ}+\mathrm{HCl}$ & $6 / 9(67)$ \\
4 & HCl alone & $0 / 6(0)^{\star}$ \\
5 & IL-1 $\beta+\mathrm{HCl}$ & $6 / 6(100)$ \\
\hline
\end{tabular}

Results were analysed by $\chi^{2}$ test.

${ }^{\star} \mathrm{p}<0.05$ compared with positive controls.

OPZ, omeprazole.

Monocytes/macrophages were stained with mouse monoclonal antibody against rat monocytes/macrophages (ED1; Serotec). Immunohistochemical staining was performed with a streptavidin-biotin peroxidase method according to the manufacturer's instructions (LSAB kit; Dako Japan). Counterstaining was performed with methyl green. For negative controls, the primary antibody was replaced with isotype matched mouse immunoglobulins or normal rabbit serum (both Dako, Japan).

COUNTING OF LFA-1 AND Mac-1 POSITIVE CELLS LFA-1 and Mac-1 positive cells in four randomly chosen areas of scarred mucosa and in four randomly chosen areas of normal mucosa 24 hours after treatment were counted. The width inspected was $0.5 \mathrm{~mm}$, while the depth of inspection depended on the height (from base to top) of the mucosa in the area of observation. The $\times 200$ objective of a light microscope was used, and regions to be inspected were measured with reference to the eyepiece of the microscope. Results are expressed as number of cells $/ \mathrm{mm}^{2}$. In addition, LFA-1 and Mac-1 positive cells were counted separately in the deep $(0.25 \mathrm{~mm}$ length from the base of the mucosa) and superficial portions of scarred mucosa $(0.25 \mathrm{~mm}$ length from the surface of the mucosa). Counting was performed without knowledge of the treatment group to which the specimens belonged.

\section{STATISTICAL ANALYSIS}

Results other than recurrence rate are expressed as mean (SEM). One way analysis of variance was used to test significance differences among treatment group means, and results were analysed by Fisher's protected least significant difference test. Differences in recurrence rate were evaluated by $\chi^{2}$ test. Differences with $\mathrm{p}$ values less than 0.05 were considered significant.

Table 2 Effect of interleukin $1 \beta(I L-1 \beta)$ and omeprazole on gastric acid secretion

\begin{tabular}{|c|c|c|c|c|}
\hline & \multicolumn{2}{|c|}{ Acid secretion $(\mu E q / 4 h)$} & \multicolumn{2}{|c|}{ Volume ( $m l / 4 h)$} \\
\hline & $0 \mathrm{~h}$ & $20 \mathrm{~h}$ & $0 \mathrm{~h}$ & $20 \mathrm{~h}$ \\
\hline Control & $277.5(62.2)$ & $279.3(29.1)$ & $4.1(0.5)$ & $4.7(0.4)$ \\
\hline OPZ & $119.5(7.2)^{\star \star}$ & $58.2(16.5)^{\star \star}$ & $2.8(0.2)^{\star \star}$ & $2.0(0.1)^{\star \star}$ \\
\hline IL-1 $\beta$ & $98.3(11.6)^{\star \star}$ & $295.2(100.8)$ & $2.0(0.1)^{\star \star}$ & $4.3(1.0)$ \\
\hline IL-1 $\beta+\mathrm{OPZ}$ & $52.3(13.5)^{\star \star}$ & $43.8(8.3)^{\star \star}$ & $1.8(0.2)^{\star \star}$ & $1.6(0.2)^{\star \star}$ \\
\hline
\end{tabular}

Rats received an intraperitoneal injection of $1 \mu \mathrm{g} / \mathrm{kg}$ IL-1 $\beta$ or vehicle and the pylorus was ligated 0 or 20 hours after injection. Omeprazole was administered 20 hours before and four hours after injection of IL-1 $\beta$ or vehicle

$\star \star \mathrm{p}<0.01$ compared with controls.

OPZ, omeprazole.

\section{Results}

ULCER RECURRENCE

In control rats killed after receiving no IL-1 $\beta$ treatment, no ulcers were detected on macroscopic examination in 12 rats found to have healed ulcers on endoscopy, and in six rats subjected to histological examination no mucosal defects were detected. No treatment caused ulcer recurrence by 24 hours (groups $1-4)$. By 48 hours, nine of 11 healed ulcers in the group treated with IL-1 $\beta$ had relapsed (positive control, group 1). Treatment with omeprazole completely prevented IL- $1 \beta$ induced ulcer recurrence ( $n=9$, group 2 ). In contrast, six of nine healed ulcers had recurred in the group given both omeprazole and $\mathrm{HCl}$ (group 3). No relapse was found in rats given $\mathrm{HCl}$ alone ( $\mathrm{n}=6$, group 4). In rats given both IL-1 $\beta$ and $\mathrm{HCl}$ (group 5), all six healed ulcers had recurred (table 1). $\mathrm{HCl}$ acid alone did not cause ulcer recurrence by 60 or 84 hours.

EFFECT OF IL-1 $\beta$ ON GASTRIC ACID SECRETION Intraperitoneal injection of $1 \mu \mathrm{g} / \mathrm{kg}$ IL- $1 \beta$ decreased acid secretion and volume by $65 \%$ and $51 \%$, respectively, at 0 hours, but these effects disappeared by 20 hours after injection (table 2). Omeprazole decreased acid secretion and volume by $57 \%$ and $32 \%$, respectively, at 0 hours (20 hours after single administration of omeprazole), and by $79 \%$ and $57 \%$, respectively, at 20 hours (16 hours after the second administration of omeprazole). Treatment with both IL-1 $\beta$ and omeprazole resulted in stronger inhibition of acid secretion than observed with either drug alone, although the differences between these treatments did not reach statistical significance; this treatment decreased acid secretion and volume by $81 \%$ and $56 \%$, respectively, at 0 hours, and by $84 \%$ and $66 \%$, respectively, at 20 hours.

\section{EXPRESSION OF ADHESION MOLECULES}

ICAM-1 was detected mainly in endothelial cells and some infiltrating cells in deep portions of scarred mucosa in healed ulcers at 0 hours (no treatment). In rats treated with IL-1 $\beta$, there was a marked increase in expression of ICAM-1 throughout the scarred mucosa (fig 1A) by 24 hours while IL- $1 \beta$ did not increase expression of ICAM-1 in normal mucosa adjacent to scarred mucosa. In rats given omeprazole and IL-1 $\beta$, expression of ICAM-1 was not increased, and few endothelial cells were stained for ICAM-1 in the superficial portion of the mucosa (fig 1B). In rats given both omeprazole and $\mathrm{HCl}$ concomitant with IL-1 $\beta$, strong expression of ICAM-1 was observed throughout the scarred mucosa, as in positive control rats. Administration of $\mathrm{HCl}$ alone did not affect ICAM-1 expression.

The mean numbers of LFA- 1 and Mac- 1 positive cells in scarred mucosa ( 0 hours) in the control group were 683 (79) and 522 (32), respectively. IL-1 $\beta$ increased the number of both LFA-1 and Mac-1 positive cells significantly by 24 hours. Administration of omeprazole inhibited the increase in the number of LFA- 1 and Mac- 1 positive cells by IL- $1 \beta$. This effect of omeprazole was eliminated by oral 

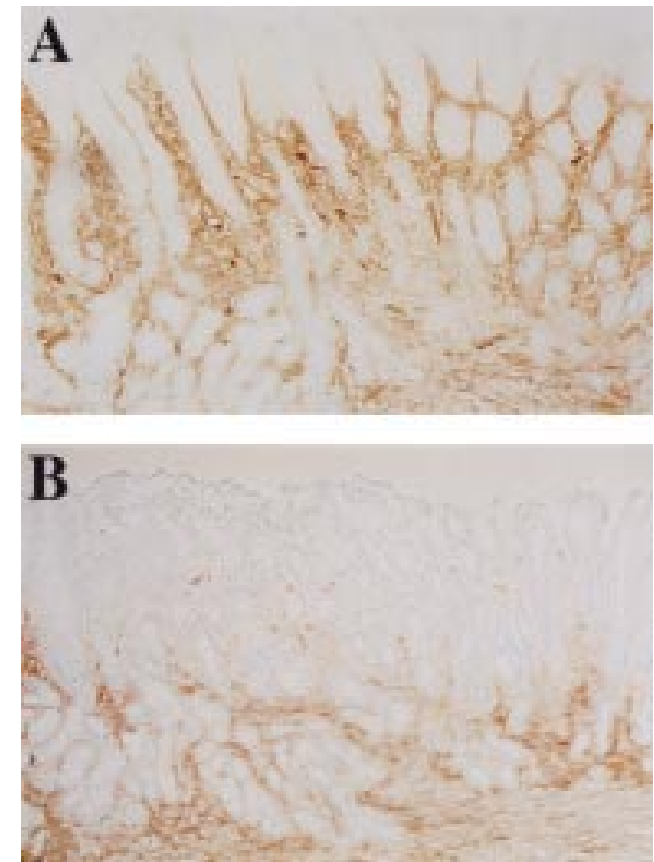

Figure 1 Expression of intercellular adhesion molecule 1 (ICAM-1) in scarred mucosa 24 hours after injection of interleukin $1 \beta(I L-1 \beta)$. A marked increase in expression of $I C A M-1$ was observed by 24 hours in rats given $I L-1 \beta$ (A) while there was no increase in expression of ICAM-1 in rats administered omeprazole together with $I L-1 \beta(B)$. Original magnification $\times 40$.

administration of acid, and numbers of LFA-1 and Mac-1 positive cells were larger than those in rats not given IL-1 $\beta$ ( 0 hours, control rats). Administration of $\mathrm{HCl}$ alone did not affect the numbers of such cells. Administration of antibody against ICAM-1 inhibited the increase in the numbers of LFA-1 and Mac-1 positive cells infiltrating scarred mucosa after injection of IL-1 $\beta$ (fig 2). No treatment affected the numbers of LFA-1 and Mac-1 positive cells in normal mucosa (fig 3 ).

In a detailed analysis of the numbers of LFA-1 and Mac-1 positive cells in both superficial and deep portions of mucosa, such cells were found to be predominant in the deep portion in non-treated rats; the mean numbers of

A

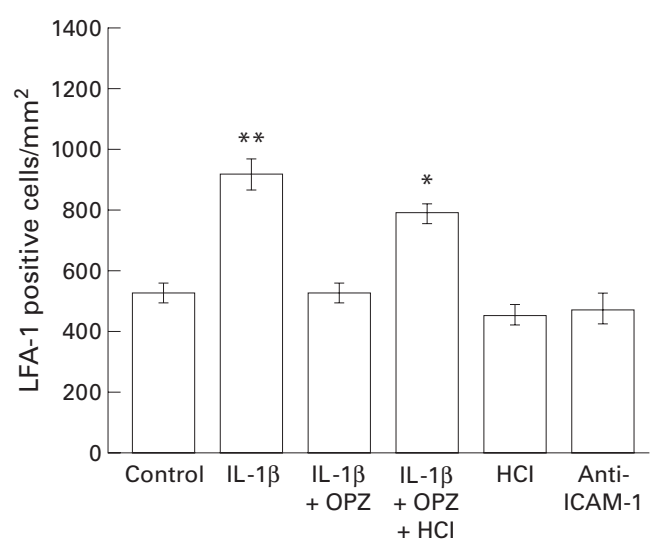

LFA-1 and Mac-1 positive cells were 369 (68) and 309 (23), respectively, in the superficial portion, and 998 (110) and 679 (58), respectively, in the deep portion of the mucosa. In the superficial portion, prominent increases in the numbers of LFA-1 and Mac-1 positive cells were observed in two groups (groups 1 and 3) in which recurrence of ulcers was noted by 48 hours (fig 4A, B) while there was only a slight but significant increase in the number of Mac-1 positive cells in the deep portion of the mucosa in rats given IL-1 $\beta$ (fig $4 \mathrm{D}$ ). No increase was observed in the number of LFA-1 positive cells in the deep portion of scarred mucosa in any of the four experimental groups (fig 4C).

Administration of antibody against ICAM-1 inhibited infiltration by both LFA-1 and Mac-1 positive leucocytes in superficial mucosa induced by IL-1 $\beta$. This antibody did not affect the numbers of such cells in the deep portion of scarred mucosa.

\section{IL- $1 \beta$ AND TNF- $\alpha$ CONCENTRATIONS IN SCAR} TISSUE

In rats given IL- $1 \beta$, concentrations of IL- $1 \beta$ and TNF- $\alpha$ in scar tissue were significantly higher by 24 hours than those in rats without IL-1 $\beta$ treatment (0 hours). Omeprazole diminished the increases in concentrations of these two cytokines, and $\mathrm{HCl}$ given together with IL-1 $\beta$ eliminated this effect of omeprazole. Administration of $\mathrm{HCl}$ alone did not affect concentrations of these two cytokines (fig 5A, B). No treatment affected concentrations of IL-1 $\beta$ and TNF- $\alpha$ in normal gastric tissue (data not shown).

EXPRESSION OF IL-1 $\beta$ AND TNF- $\alpha$

In rats not given IL- $1 \beta$ treatment ( 0 hours), infiltration by inflammatory leucocytes was observed mainly in the deep portion of the mucosa. Immunoreactive IL- $1 \beta$ and TNF- $\alpha$ were detected mainly in such inflammatory cells in the deep mucosa. By 24 hours after injection of IL-1 $\beta$, numbers of leucocytes, including neutrophils and monocytes/ macrophages, were increased in the superficial portion of scarred mucosa (fig $6 \mathrm{~A}, \mathrm{~B}$ ). IL-1 $\beta$

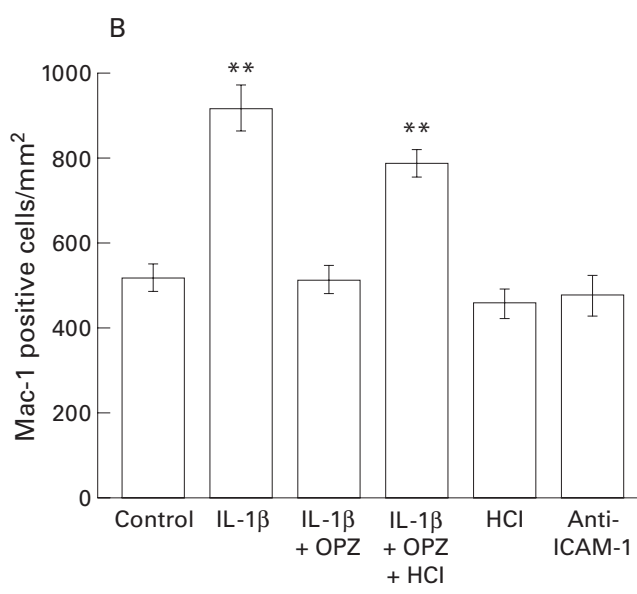

Figure 2 Comparison of numbers of infiltrating leucocytes positive for lymphocyte function associated antigen 1 (LFA-1) or Mac-1 in scarred mucosa. The numbers of LFA-1 or Mac-1 positive cells infiltrating scarred mucosa were counted, and the mean numbers of such cells were compared with those in control animals (not given IL-1B). Results are mean (SEM), $n=6$. OPZ, omeprazole; IL-1 $\beta$, interleukin $1 \beta ;$ ICAM-1, intercellular adhesion molecule $1 .{ }^{*} p<0.05,{ }^{\star} * 00.01$ compared with control animals. 
(fig 6C) and TNF- $\alpha$ (fig 6D) were detected in these inflammatory leucocytes in the superficial portion of the mucosa. In the submucosal layer, a few infiltrating cells were stained for IL- $1 \beta$ and TNF- $\alpha$. Similar results were obtained for rats given both omeprazole and $\mathrm{HCl}$ concomitant with IL-1 $\beta$. In rats given both IL-1 $\beta$ and omeprazole, $\mathrm{HCl}$ alone, or the antibody against ICAM-1 (fig $6 \mathrm{E}, \mathrm{F}$ ), the numbers of cells stained for IL- $1 \beta$ and TNF- $\alpha$ was small.

\section{Discussion}

In our previous study, we demonstrated that IL-1 $\beta$ markedly increased infiltration by leucocytes in the superficial portion of scarred mucosa prior to ulcer recurrence, and that adhesion molecules play a crucial role in this ulcer recurrence. ${ }^{3}$ In this study, we found that IL- $1 \beta$ challenge enhanced ICAM-1 expression, increased infiltration by LFA-1 and Mac-1 positive cells, and stimulated production of

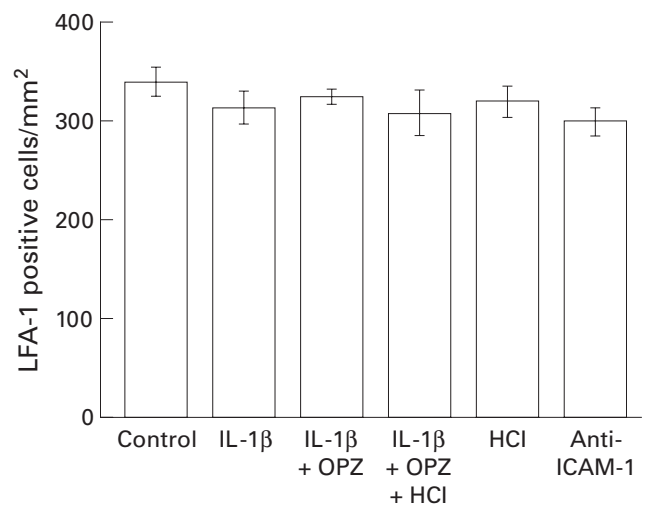

B

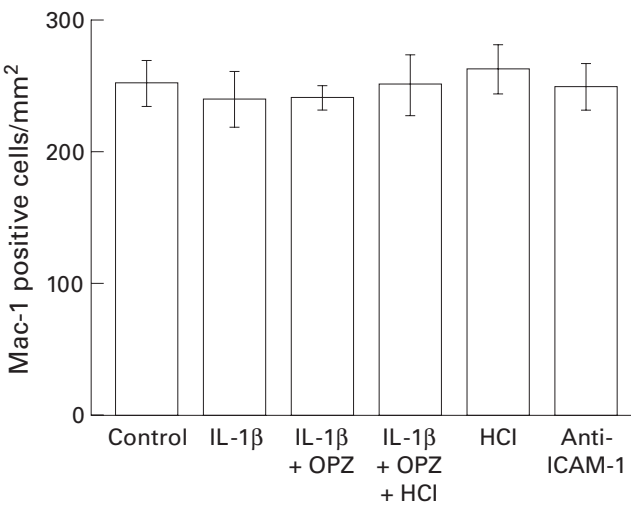

Figure 3 Comparison of numbers of infiltrating leucocytes positive for lymphocyte function associated antigen 1 (LFA-1) or Mac-1 in normal mucosa. The numbers of LFA-1 or Mac-1 positive cells infiltrating the normal mucosa were counted, and the mean numbers of such cells were compared with those in control animals (not given IL-1 $\beta$ ). Results are mean (SEM), $n=6$. OPZ, omeprazole; IL-1 $\beta$, interleukin $1 \beta ; I C A M-1$, intercellular adhesion molecule 1 .

A

LFA-1 (superficial mucosa)

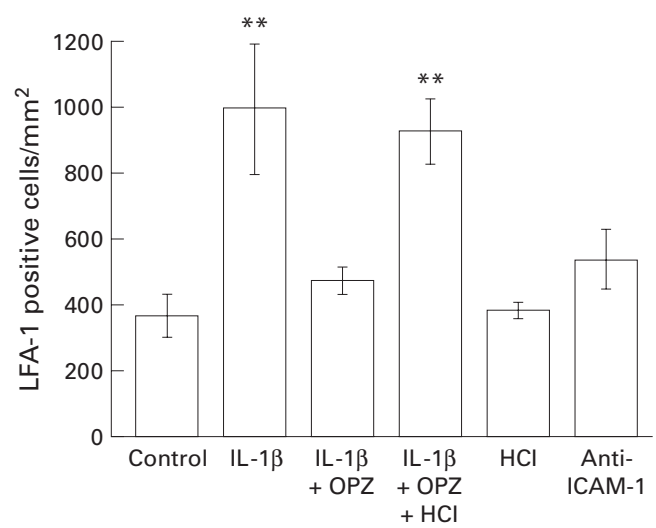

C

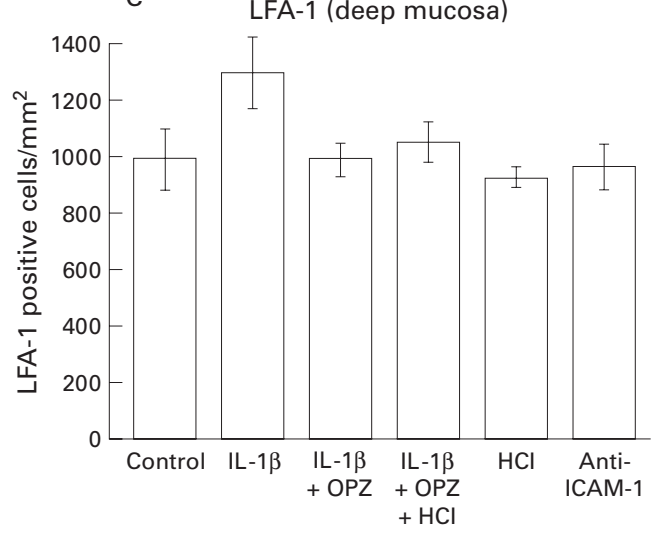

Mac-1 (superficial mucosa)

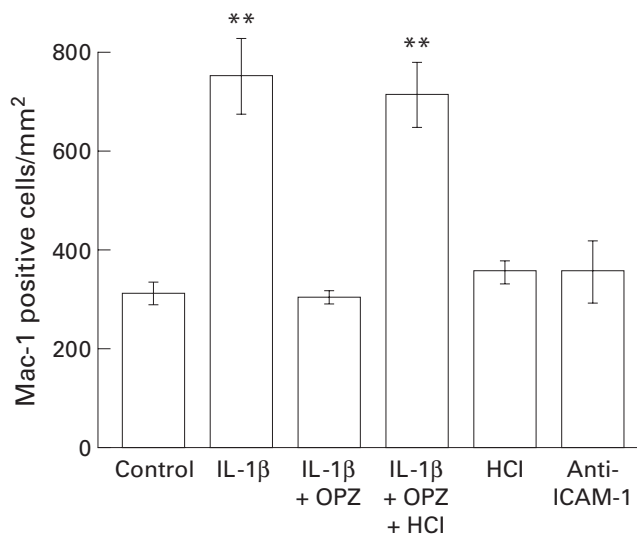

D

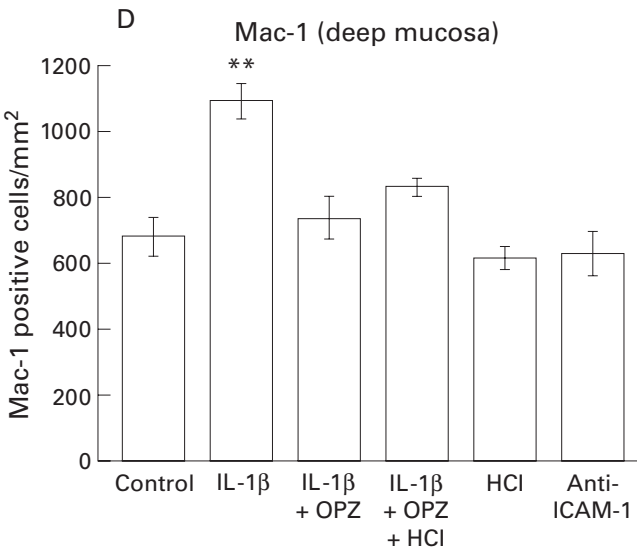

Figure 4 Comparison of numbers of lymphocyte function associated antigen 1 (LFA-1) and Mac-1 positive leucocytes in superficial and deep portions of scarred mucosa at 24 hours. LFA-1 and Mac-1 positive cells were counted separately in the deep and superficial portions of scarred mucosa, and the mean numbers of cells were compared with those in control animals

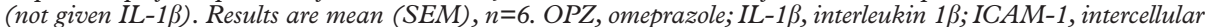
adhesion molecule $1 .{ }^{\star *} p<0.01$ compared with control animals. 
IL-1 $\beta$ and TNF- $\alpha$ in the superficial portion of scarred mucosa. These inflammatory responses may thus play a crucial role in IL- $1 \beta$ induced ulcer recurrence. We also found that sufficient inhibition of gastric acid by omeprazole inhibited both ulcer recurrence and these responses, and that these inhibitory effects of omeprazole were abolished by application of $0.15 \mathrm{~N} \mathrm{HCl}$.
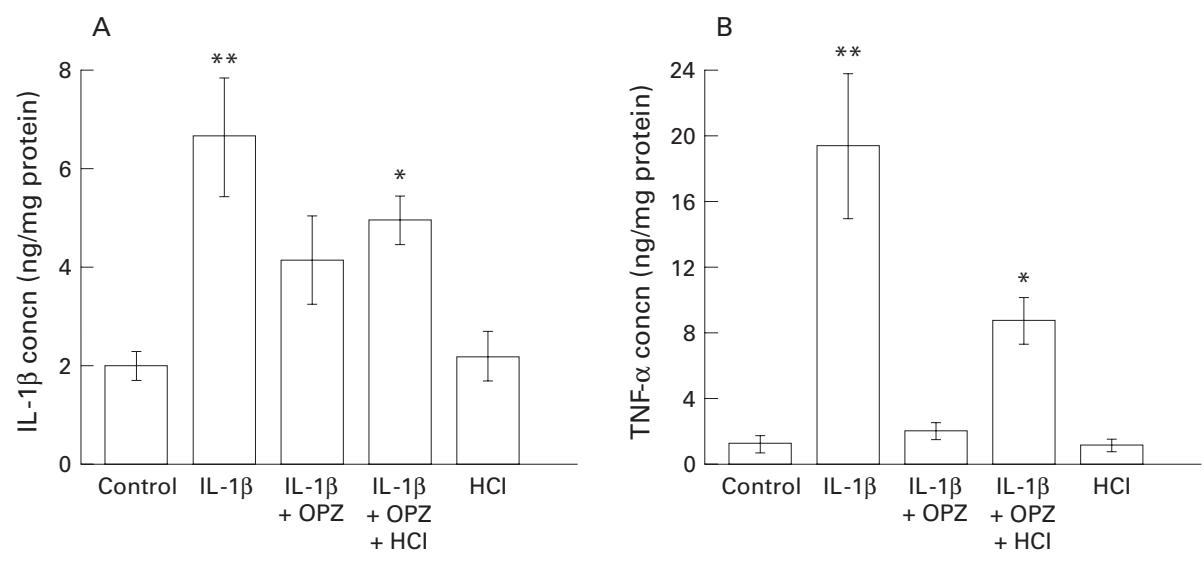

Figure 5 Interleukin $1 \beta(I L-1 \beta)$ and tumour necrosis factor $a(T N F-\alpha)$ concentrations in scar tissue at 24 hours. Concentrations of $I L-1 \beta(A)$ and $T N F-\alpha(B)$ in scar tissue were assayed 24 hours after $I L-1 \beta$ treatment. Results are mean $(S E M), n=6$. OPZ, omeprazole. ${ }_{p} p<0.05,{ }^{*}{ }_{p}<0.01$ compared with control animals (not given IL-1 $\beta$ ).
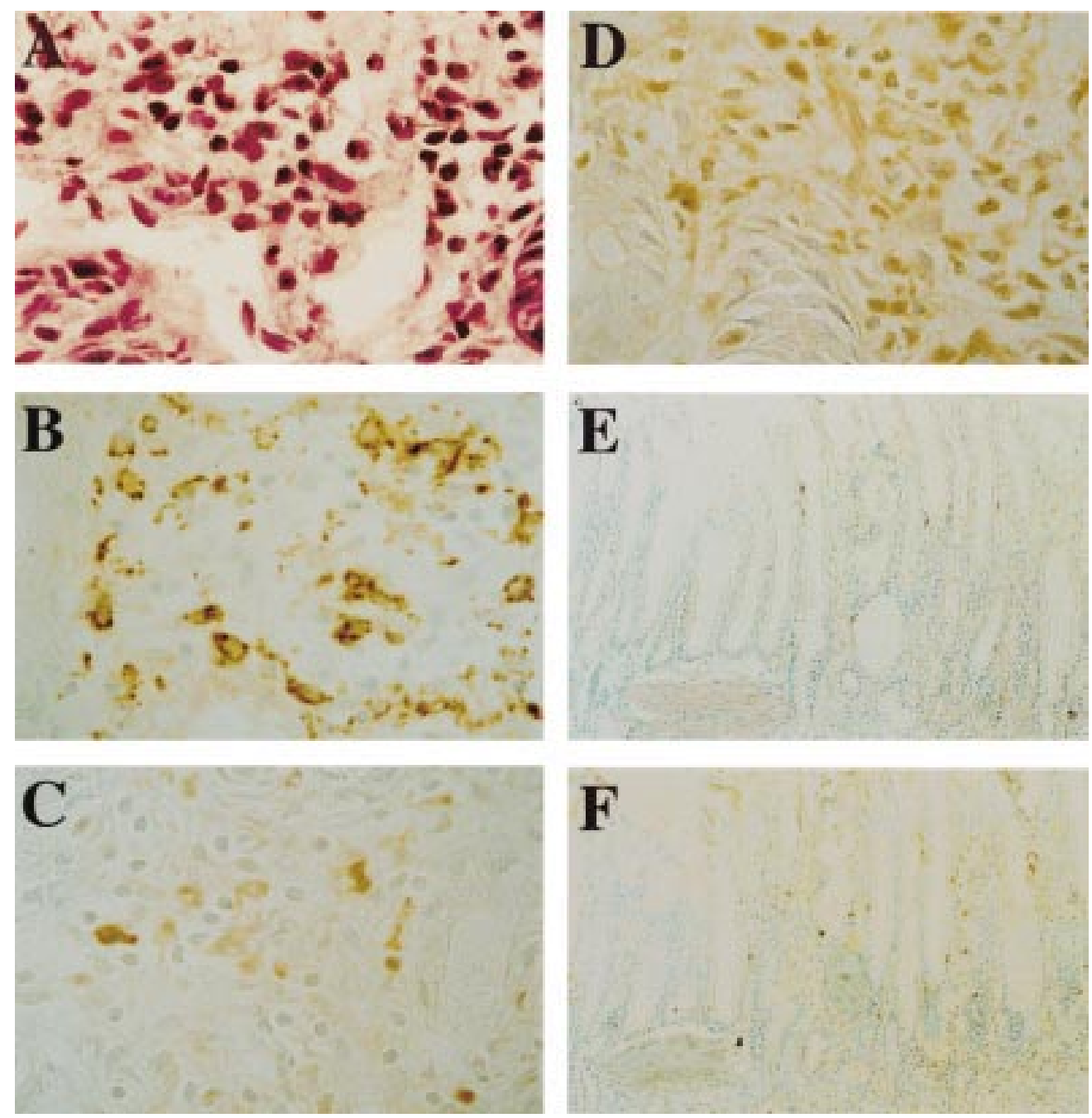

Figure 6 Cellular infiltration and immunohistochemical staining for interleukin $1 \beta(I L-1 \beta)$ and tumour necrosis factor a (TNF- $\alpha$ ) in superficial mucosa at 24 hours after IL-1 $\beta$ treatment. (A) IL-1 $\beta$ induced infiltration by leucocytes, including neutrophils, in the superficial portion of scarred mucosa. (B) Monocytes/macrophages were abundant in this region. IL-1 $\beta$ $(C)$ and TNF- $\alpha(D)$ were detected mainly in inflammatory cells in the superficial mucosa. The numbers of cells stained for $I L-1 \beta(E)$ and TNF- $a(F)$ were small in rats given the antibody against intercellular adhesion molecule 1. Original magnification $\times 200(A-D)$ and $\times 50(E, F)$. 
These results suggest that acid may enhance gastric mucosal inflammation in response to IL-1 $\beta$ stimulation, resulting in gastric ulcer recurrence.

Mucosal damage occurs primarily in the superficial portion of scarred mucosa where neutrophils have accumulated, and this superficial damage develops into deep ulceration over time, ${ }^{3}$ suggesting that ulcers recur from the mucosal side and quickly develop deeper into the tissue, possibly with the aid of acid back diffusion and/or microcirculatory disturbance. The antibody against ICAM-1 almost completely inhibited IL- $1 \beta$-induced increases in the number of leucocytes positive for LFA-1 and Mac-1. Therefore, increased expression of ICAM-1 in the superficial portion of scarred mucosa may cause infiltration by leucocytes, including neutrophils, and may be important as an initial event in gastric ulcer recurrence.

IL- $1 \beta$ and TNF- $\alpha$ have many biological activities, ${ }^{13}$ and induce inflammation and injury in a variety of tissues. ${ }^{14-16}$ We found that exogenous IL-1 $\beta$ challenge increased concentrations of endogenous IL-1 $\beta$ and TNF- $\alpha$ in scarred mucosa but not in normal mucosa. The main source of these cytokines was inflammatory cells such as macrophages located in the superficial portion of scarred mucosa. Furthermore, antibodies against LFA-1 and Mac-1 inhibited IL- $1 \beta$ induced infiltration by macrophages, and inhibited the increase in ICAM-1 expression in the superficial portion of scarred mucosa (Watanabe, unpublished data). These cytokines released from inflammatory cells may thus contribute to overexpression of ICAM-1 in the superficial portion of scarred mucosa which leads to infiltration by many leucocytes expressing LFA-1 and Mac-1. Ulcers can thus recur at the same site as previous ulcers.

IL-1 $\beta$ is known to inhibit acid secretion but the extent of inhibition differs depending on the route of IL-1 $\beta$ administration. ${ }^{17-19}$ Intraperitoneal injection of IL- $1 \beta$ at the dose used in this study inhibited basal acid secretion by approximately $65 \%$ but only early after injection. This effect did not continue until 20 hours after injection, suggesting that gastric acid is present prior to induction of ulcer recurrence by IL-1 $\beta$. All of six healed ulcers had recurred following concurrent administration of exogenous acid with IL- $1 \beta$ while two of 11 healed ulcers did not after administration of IL- $1 \beta$ alone. IL- $1 \beta$ may thus be a more potent inducer of gastric ulcer recurrence under conditions of full or increased gastric acid secretion.

Gastric acid itself is believed to directly cause mucosal damage. However, it is unlikely that gastric acid alone caused recurrence of ulcers in our experimental model as $\mathrm{HCl}$ alone did not cause ulcer recurrence, and in a previous study neutralisation of neutrophils with antiserum prevented induction of ulcer recurrence by IL- $1 \beta$ without affecting acid secretion. ${ }^{3}$ To the best of our knowledge there are no reports suggesting possible mechanisms of acid induced mucosal injury other than direct injury.
The findings that increase in leucocyte infiltration, overexpression of adhesion molecules (ICAM-1, LFA-1, and Mac-1), and stimulation of IL- $1 \beta$ and TNF- $\alpha$ production caused by administration of IL- $1 \beta$ were inhibited by omeprazole, and that these effects of omeprazole were abolished by acidification of the gastric lumen, suggest that acid assists in upregulation of the inflammatory process leading to recurrence of ulcer. Neutrophils and adhesion molecules play a crucial role in many gastric injuries such as those resulting from ethanol or indomethacin administration. ${ }^{20-22}$ As these gastric injuries are prevented by inhibition of gastric acid secretion, gastric acid may stimulate gastric mucosal inflammation.

PPIs such as omeprazole may affect inflammation regardless of their effect on inhibition of acid secretion. Recent in vitro studies have demonstrated that omeprazole modulates neutrophil functions such as inhibition of oxygen derived free radical production and degradation of glucuronidase and lysozyme. ${ }^{23}{ }^{24}$ However, in the present study, $\mathrm{HCl}$ abolished prevention of ulcer recurrence by omeprazole and inhibition by omeprazole of overexpression of adhesion molecules and stimulation of IL- $1 \beta$ and TNF- $\alpha$ production. Omeprazole may thus prevent ulcer recurrence mainly by marked inhibition of acid secretion, and its direct effect on neutrophil functions, if any, may be small in vivo.

Our findings indicate that both gastric acid and exogenously administered IL- $1 \beta$ are required for enhancement of inflammation in scarred mucosa and recurrence of gastric ulcers in our model. Concentrations of endogenous IL- $1 \beta$ and TNF- $\alpha$ in scarred mucosa were increased after challenge with exogenous IL-1 $\beta$. Many investigators have demonstrated that concentrations of these cytokines in the gastric mucosa are increased in patients with $H$ pylori associated gastritis. ${ }^{25} 26$ This phenomenon is thought to be responsible for leucocytic infiltration into gastric mucosa. There are few reports demonstrating expression of cytokines in scarred mucosa. We previously reported that eradication of $H$ pylori significantly inhibited infiltration of both neutrophils and mononuclear cells in scarred mucosa. ${ }^{27}$ This finding suggests that overexpression of cytokines may also occur in scarred mucosa in patients with $H$ pylori infection. Sufficient inhibition of gastric acid maintains remission of peptic ulcer disease even in the presence of $H$ pylori infection, which causes production of inflammatory cytokines such as IL-1 $\beta$ and TNF- $\alpha$, although cure of $H$ pylori infection results in marked reduction of ulcer recurrence without the need for inhibition of acid secretion. ${ }^{28}{ }^{29}$ These findings suggest that both gastric acid and inflammatory cytokines may both play a crucial role in peptic ulcer recurrence. Sufficient gastric acid and inflammatory stimulation by $H$ pylori may act in concert, leading to enhancement of inflammation and induction of ulcer recurrence, while neither of these factors alone may have an effect on enhancement of inflammation in scarred mucosa sufficient for such induction. 
In conclusion, in the experimental model we tested, recurrence of experimental gastric ulcers caused by IL- $1 \beta$ required gastric acid. Acid stimulates the inflammatory process, including expression of adhesion molecules and leucocyte infiltration, in scarred mucosa in the presence of IL-1 $\beta$. This process may contribute to ulcer recurrence. The results of this study may explain why PPIs prevent recurrence of peptic ulcer disease even in the presence of inflammatory stimulation by cytokines in response to $H$ pylori infection.

1 Lauritsen K, Andersen BN, Laursen LS, et al. Omeprazole $20 \mathrm{mg}$ three days a week and $10 \mathrm{mg}$ daily in prevention of duodenal ulcer relapse. Gastroenterology 1991;100:663-9.

2 Gudmand-Høyer E, Jensen KB, Krag E, et al. Prophylactic effect of cimetidine in duodenal ulcer disease. BMF effect of cime

3 Watanabe T, Arakawa T, Fukuda T, et al. Role of neutrophils in a rat model of gastric ulcer recurrence caused by IL-1 $\beta$. in a rat model of gastric ulcer

4 Mulligan MS, Ward PA. Immune complex-induced lung and dermal vascular injury: differing requirements for tumor necrosis factor- $\alpha$ and IL-1. F Immunol 1992;149: $331-9$

5 Pettipher ER, Higgs GA, Henderson B. Interleukin 1 induces leukocyte infiltration and cartilage proteoglycan degradation in the synovial joint. Proc Natl Acad Sci USA 1986;83:8749-53.

6 Dayer J-M, de Rochemonteix B, Burrus B, et al. Human recombinant interleukin 1 stimulates collagenase and prostaglandin E2 production by human synovial cells. $\mathcal{F}$ Clin Invest 1986;77:645-8.

7 Pober JS, Bevilacqua MP, Mendrick DL, et al. Monokines, interleukin 1 and tumor necrosis factor, each independently induce biosynthesis and transient expression of the same antigen on the surface of cultured human

8 Takagi K, Okabe S, Saziki R. A new method for the production of chronic gastric ulcer in rats and the effect of several tion of chronic gastric ulcer in rats and the effect of severa

9 Fukawa K, Kawano O, Misaki N, et al. Experimental studies on gastric ulcer. 4. Sequential observation and evaluation of gastric ulcers by endoscope in the rat. $\mathcal{F p n}^{\mathrm{F}}$ Pharmaco 1983;33:175-9.

10 Segawa K, Nakazawa S, Tsukamoto Y, et al. Effect of omeprazole on gastric acid secretion in rat: evaluation of dose, duration of effect, and route of administration. Gastroentero fpn 1987;22:413-18.

11 Tamatani T, Miyasaka M. Identification of monoclonal antibodies reactive with the rat homolog of ICAM-1 and evidence for a differential involvement of ICAM-1 in the adhe for endothelial cells. Int Immunol 1990;2:165-71.
12 Brenner AJ, Harris ED. A quantitative test for copper using bicinchonic acid. Anal Biochem 1995;226:80-4.

13 Le J, Vilcek J. Tumor necrosis factor and interleukin 1. Cytokines with multiple overlapping biological activities. Lab Invest 1987;56:234-48.

14 Diamond JR, Pesek I. Glomerular tumor necrosis factor and interleukin 1 during acute aminonucleoside nephrosis. $L a b$ Invest 1991;64:21-8.

15 Sansonetti PJ, Arondel J, Cavaillon J-M, et al. Role of interleukin-1 in the pathogenesis of experimental shigellosis. 7 Clin Invest 1995;96:884-92.

16 Santucci L, Fiorucci S, Maria F, et al. Role of tumor necrosis factor $\alpha$ release and leukocyte margination in indomethacin-induced gastric injury in rats. Gastroenterology 1995;108:393-401

17 Robert A, Olafsson AS, Lancaster C, et al. Interleukin-1 is cytoprotective, antisecretory, stimulates $\mathrm{PGE}_{2}$ synthesis by the stomach, and retards gastric emptying. Life Sci 1991;48:123-34.

18 Uehara A, Okumura T, Sekiya C, et al. Interleukin-1 inhibits the secretion of gastric acid in rats: possible involvement of prostaglandin. Biochem Biophys Res Commun 1989;162: 1578-84.

19 Saperas E, Tache Y. Central interleukin-1 $\beta$-induced inhibition of acid secretion in rats. Life Sci 1992;52:785-92.

20 Kvietys PR, Twohig B, Danzell J, et al. Ethanol-induced injury to the rat gastric mucosa: role of neutrophils and xanthine oxidase-derived radicals. Gastroenterology 1990; 98:909-20.

21 Wallace JL, Arfors K-E, McKnight GW. A monoclonal antibody against the CD18 leukocyte adhesion molecule prevents indomethacin-induced gastric damage in the rabbit. Gastroenterology 1991;100:878-83.

22 Andrews FJ, Malcontenti-Wilson C, O'Brian PE. Effect of nons nonsteroidal antinflammatory drugs on LFA-1 and 26:G657-64.

23 Wandall JH. Effects of omeprazole on neutrophil chemotaxis, superoxide production, degranulation, and translocation of cytochrome ${ }_{\mathrm{b}-245}$. Gut 1992;33:617-21.

24 Suzuki M, Mori M, Miura S, et al. Omeprazole attenuates oxygen-derived free radical production from human neutrophils. Free Radic Biol Med 1996;21:727-31.

25 Crabtree JE, Shallcross TM, Heatley RV, et al. Mucosal tumour necrosis factor $\alpha$ and interleukin-6 in patients with Helicobacter pylori associated gastritis. Gut 1991;32:1473-7.

26 Noach LA, Bosma NB, Jansen J, et al. Mucosal tumor necrosis factor- $\alpha$, interleukin- $1 \beta$, and interleukin- 8 producnecrosis factor- $\alpha$, interleukin- $1 \beta$, and interleukin- 8 produc-
tion in patients with Helicobacter pylori infection. Scand 7 Gastroenterol 1994;29:425-9.

27 Higuchi K, Arakawa T, Nebiki H, et al. Rebamipide prevents recurrence of gastric ulcers without affecting Helicobacter pylori status. Dig Dis Sci 1998;43(suppl):S99-106.

28 Marshall BJ, Goodwin CS, Warren JR, et al. Prospective double-blind trial of duodenal ulcer recurrence after eradication of Campylobacter pylori. Lancet 1988;2:1437-42.

29 Graham DY, Lew GM, Klein PD, et al. Effect of treatment of Helicobacter pylori infection on the long-term recurrence of gastric or duodenal ulcer: a randomized, controlled study. Ann Intern Med 1992;116:705-8. 